\title{
Predictive significance of thyroid transcription factor-1 expression in patients with non-squamous non-small cell lung cancer with wild-type epidermal growth factor receptor treated with erlotinib
}

\author{
YOSHIRO NAKAHARA ${ }^{1,2}$, YUKIO HOSOMI ${ }^{1}$, MAKOTO SAITO $^{3}$, MASUMI OGAWA $^{4}$, \\ TSUNEKAZU HISHIMA ${ }^{4}$, TATSURU OKAMURA ${ }^{1}$, JIICHIRO SASAKI $^{5}$ and NORIYUKI MASUDA ${ }^{2}$
}

\begin{abstract}
${ }^{1}$ Department of Thoracic Oncology and Respiratory Medicine, Tokyo Metropolitan Cancer and Infectious Diseases Center, Komagome Hospital, Tokyo 113-8677; ${ }^{2}$ Department of Respiratory Medicine, Kitasato University School of Medicine, Sagamihara, Kanagawa 252-0374; ${ }^{3}$ Department of Clinical Research Support; ${ }^{4}$ Department of Pathology, Tokyo Metropolitan Cancer and Infectious Diseases Center, Komagome Hospital, Tokyo 113-8677;

${ }^{5}$ Research and Development Center for New Medical Frontiers, Kitasato University

School of Medicine, Sagamihara, Kanagawa 252-0374, Japan
\end{abstract}

Received September 15, 2015; Accepted April 15, 2016

DOI: $10.3892 / \mathrm{mco} .2016 .870$

\begin{abstract}
Little is known on the efficacy of erlotinib treatment in patients expressing wild-type epidermal growth factor receptor (EGFR). This study is a retrospective review of patients with non-squamous, non-small-cell lung cancer (NS-NSCLC) and wild-type EGFR who were treated with erlotinib alone as second- or later-line chemotherapy at the Tokyo Metropolitan Cancer and Infectious Diseases Center of Komagome Hospital (Tokyo, Japan) between December, 2008 and December, 2013. Thyroid transcription factor-1 (TTF-1) was immunohistochemically analyzed in 26 of 53 patients, among whom $20(77 \%)$ and $6(23 \%)$ were considered as TTF-1-positive and -negative, respectively. The median follow-up of these 26 patients was 133 days (range, 26-873 days). The time-to-treatment failure was significantly longer in TTF-1-positive compared with that in TTF-1-negative patients [49.5 vs. 20.0 days; $95 \%$ confidence interval (CI): $28-90$ vs. $14-74$ days, respectively; $\mathrm{P}=0.01]$. The overall survival was significantly better for TTF-1-positive (227 days; 95\% CI: 110-366 days) compared with TTF-1-negative patients ( $\mathrm{P}=0.0002)$. Therefore, the expression of TTF-1 may serve as a useful tool for predicting the efficacy of erlotinib in patients with NS-NSCLC expressing wild-type EGFR.
\end{abstract}

Correspondence to: Dr Yoshiro Nakahara, Department of Respiratory Medicine, Kitasato University School of Medicine, 1-15-1 Kitasato Minami-Ku, Sagamihara, Kanagawa 252-0374, Japan E-mail: md100062@kitasato-u.ac.jp

Key words: thyroid transcription factor-1, erlotinib, non-squamous non-small-cell lung cancer

\section{Introduction}

Several studies have reported that patients with advanced non-small-cell lung cancer (NSCLC) with EGFR-activated mutations respond remarkably to EGFR tyrosine-kinase inhibitors (TKIs) (1-4). However, the role of EGFR-TKIs in patients with wild-type EGFR remains unclear.

Erlotinib is a small-molecule EGFR-TKI that has improved the overall survival (OS) of patients with previously treated unselected advanced NSCLC (5). Therefore, erlotinib has been approved as second-line treatment for such patients.

Smoking status is significantly associated with tumor response. However, data on the effectiveness of erlotinib treatment in patients expressing wild-type EGFR are limited.

Thyroid transcription factor-1 (TTF-1) is tissue-specific, being expressed mainly in the lungs and thyroid gland. Squamous cell carcinomas of the lung express TTF-1 less frequently compared with non-squamous cell carcinoma $(6,7)$. A history of smoking is closely associated with squamous cell carcinoma.

Therefore, the aim of this study was to determine whether TTF-1 may serve as a predictive biomarker of the efficacy of erlotinib.

\section{Patients and methods}

Patients. The study population comprised patients with non-squamous (NS)-NSCLC expressing wild-type EGFR, who were treated with erlotinib as second- or later-line chemotherapy at the Tokyo Metropolitan Cancer and Infectious Diseases Center, Komagome Hospital (Tokyo, Japan) between December, 2008 and December, 2013. The Institutional Review Board of Tokyo Metropolitan Cancer and Infectious Diseases Center of Komagome Hospital approved the protocol of this study and waived the need for patient written informed consent, as routine medical data were analyzed under complete anonymity. 
Erlotinib therapy. All patients underwent a baseline assessment and received oral erlotinib (150 mg/day) $1 \mathrm{~h}$ before meals, until detection of progressive disease (PD) or intolerable toxicity. Subsequent doses of erlotinib were modified based on toxicity at the discretion of the treating physician.

Immunohistochemical analysis of TTF-1 expression. Lung cancer was diagnosed from tissue samples collected during surgery, bronchoscopy, or computed tomography-guided biopsy. All the samples were cut into $4-\mu \mathrm{m}$ sections and embedded in paraffin. Antigen retrieval was performed by autoclaving the sections at $121^{\circ} \mathrm{C}$ for $15 \mathrm{~min}$ in citrate buffer ( $\mathrm{pH}$ 6.0). The sections were then incubated for $2 \mathrm{~h}$ at room temperature with mouse monoclonal anti-TTF-1 antibody (clone SPT24; dilution, 1:300; cat. no. NCL-L-TTF-1; Leica Microsystems K.K., Tokyo, Japan). Primary antibody binding to the tissue sections was detected using Elite ABC kits (Vector Laboratories Inc., Burlingame, CA, USA). A pathologist (T.H.) who was blinded to the clinical information reviewed the immunostained sections, which were considered as positive when cytoplasmic or nuclear staining was evident.

Statistical methods. Differences in characteristics were evaluated using the $\chi^{2}$ test. Time-to-treatment failure (TTF) was defined as the number of days that elapsed between the initiation of erlotinib treatment and the date of initiation of any type of subsequent therapy, or a request from the patient to terminate the erlotinib treatment, or death. Follow-up duration was defined as the number of days that elapsed from the initiation of erlotinib treatment until the date of death or last follow-up. Subsequent therapy included chemotherapy, radiotherapy and tumor resection.

OS was defined as the number of days that elapsed between the initiation of erlotinib treatment and death from any cause. TTF and OS were estimated using the Kaplan-Meier method and intergroup comparisons were assessed using log-rank tests. The effects of 6 factors associated with patient characteristics and of previous chemotherapy on TTF and OS were evaluated using univariate analysis with the Cox proportional hazards model. Statistical significance was defined as $\mathrm{P}<0.05$. All statistical data were analyzed using JMP version 9.0 software (SAS Institute, Cary, NC, USA).

\section{Results}

Patient characteristics. We immunohistochemically analyzed TTF-1 in 26 of 53 patients treated with erlotinib monotherapy as second- or later-line chemotherapy at our hospital between December, 2008 and December, 2013. Among them, 20 (77\%) and $6(23 \%)$ patients were considered as TTF-1-positive (group A) and -negative (group B), respectively. The median age was 65 years (range, 43-77 years). Of the 26 patients, $12(46 \%)$ and $14(54 \%)$ were male and female, respectively. The performance status score was 0,1 and 2 in $5(19 \%), 15(58 \%)$ and $6(23 \%)$ patients, respectively, whereas 18 patients $(69 \%)$ were current or former smokers. Erlotinib was administered as second-, third- and fourth- or further-line treatment to $4(15 \%), 17(65 \%)$ and $5(19 \%)$ patients, respectively. There were no significant differences between groups $\mathrm{A}$ and $\mathrm{B}$ in these patient characteristics (Table I).
Table I. Patient characteristics according to the expression of thyroid transcription factor-1 (TTF-1).

\begin{tabular}{lccc}
\hline & \multicolumn{2}{c}{ TTF-1 expression } & \\
\cline { 2 - 3 } Characteristics & $\begin{array}{c}\text { Positive } \\
(\mathrm{n}=20)\end{array}$ & $\begin{array}{c}\text { Negative } \\
(\mathrm{n}=6)\end{array}$ & P-value \\
\hline Gender & & & 0.47 \\
Male & 10 & 2 & \\
Female & 10 & 4 & \\
Age, years & & & 0.06 \\
$\geq 75$ & 20 & 5 & \\
$<75$ & 0 & 1 & 0.88 \\
Smoking status & & & \\
Never & 6 & 2 & 0.37 \\
Ever & 14 & 4 & \\
Prior chemotherapy & & & \\
1 & 4 & 0 & \\
2 & 13 & 4 & \\
$\geq 3$ & 3 & 2 & \\
Performance status & & & \\
0 & 5 & & \\
1 & 11 & & \\
2 & 4 & & \\
\hline
\end{tabular}

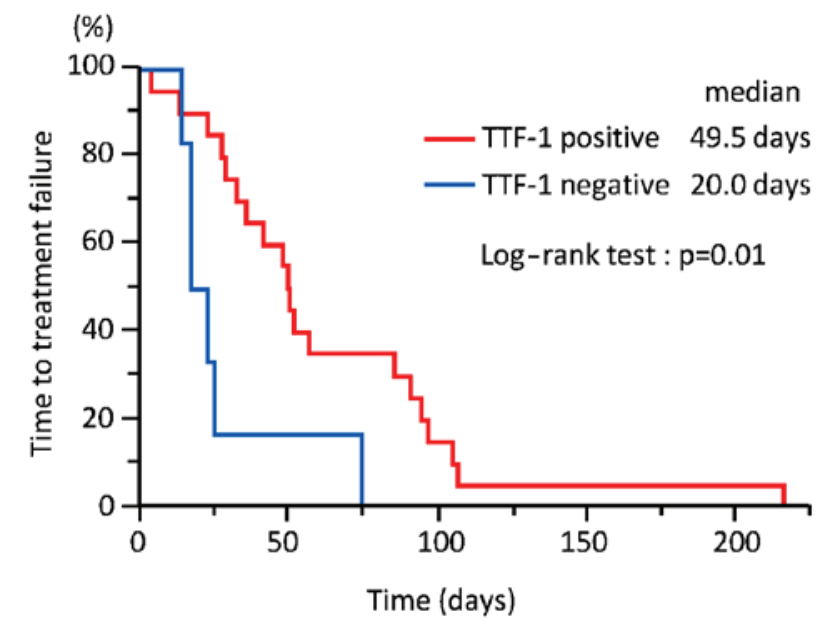

Figure 1 . The time to treatment failure was significantly longer in thyroid transcription factor-1 (TTF-1)-positive compared with that in TTF-1-negative patients ( 49.5 vs. 20.0 days; $95 \%$ confidence interval: $28-90$ vs. $14-74$ days, respectively; $\mathrm{P}=0.01$ )

Effects of erlotinib. The median follow-up of the 26 patients was 133 days (range, 26-873 days). As shown in Fig. 1, the TTF was significantly longer in group A compared with that in group B [49.5 vs. 20.0 days; $95 \%$ confidence interval (CI): $28-90$ vs. $14-74$ days, respectively; $\mathrm{P}=0.01]$. On univariate analysis, only TTF-1 was a statistically significant predictor of longer TTF (Table II). As shown in Fig. 2, OS was significantly longer in group A compared with that in group B (227 vs. 76 days; $95 \%$ CI: $110-366$ vs. 26-90 days, respectively; 
Table II. Time-to-treatment failure according to patient characteristics $(n=26)$.

\begin{tabular}{|c|c|c|c|c|}
\hline \multirow[b]{2}{*}{ Characteristics } & \multirow[b]{2}{*}{ No. of patients $(\%)$} & \multicolumn{3}{|c|}{ Univariate analysis } \\
\hline & & HR & $95 \% \mathrm{CI}$ & $\mathrm{P}$-value \\
\hline Gender & & & & 0.18 \\
\hline Male & $12(46)$ & 1.79 & $0.77-4.28$ & \\
\hline Female & $14(54)$ & & & \\
\hline Age, years & & & & 0.19 \\
\hline$\geq 75$ & $1(4)$ & 5.79 & $0.30-39.15$ & \\
\hline$<75$ & $25(96)$ & & & \\
\hline Smoking status & & & & 0.12 \\
\hline Never & $8(31)$ & 0.51 & $0.20-1.19$ & \\
\hline Ever & $18(69)$ & & & \\
\hline Prior chemotherapy & & & & $0.24^{\mathrm{a}} / 0.24^{\mathrm{b}}$ \\
\hline 1 & $4(15)$ & $0.50^{\mathrm{a}} / 0.42^{\mathrm{b}}$ & $0.12-1.51^{\mathrm{a}}$ & \\
\hline 2 & $17(65)$ & & $0.08-1.78^{\mathrm{b}}$ & \\
\hline$\geq 3$ & $5(19)$ & & & \\
\hline Performance status & & & & $0.95^{\mathrm{c}} / 0.25^{\mathrm{d}}$ \\
\hline 0 & $5(19)$ & $1.03^{\mathrm{c}} / 0.49^{\mathrm{d}}$ & $0.33-2.80^{\mathrm{c}}$ & \\
\hline 1 & $15(58)$ & & $0.14-1.66^{\mathrm{d}}$ & \\
\hline 2 & $6(23)$ & & & \\
\hline TTF-1 & & & & 0.03 \\
\hline Positive & $20(77)$ & 0.30 & $0.11-0.88$ & \\
\hline Negative & $6(23)$ & & & \\
\hline
\end{tabular}

aValues when analyzed between 1 and $2 .{ }^{b}$ Values when analyzed between 1 and $\geq 3$. ${ }^{\mathrm{c}}$ Values when analyzed between 0 and $1 .{ }^{\mathrm{d}}$ Values when analyzed between 0 and 2. CI, confidence interval; HR, hazard ratio; TTF-1, thyroid transcription factor- 1 .

$\mathrm{P}=0.0002)$. On univariate analysis, only TTF-1 was a statistically significant predictor of longer OS (Table III).

Post-erlotinib chemotherapy. As shown in Table IV, 11 (55\%) patients in group A were treated with at least one chemotherapeutic regimen after erlotinib therapy, whereas none of the patients in group B received post-erlotinib therapy. The proportion of patients who were treated with chemotherapy following erlotinib was significantly higher in group A compared with group $\mathrm{B}(\mathrm{P}=0.0049)$.

\section{Discussion}

The present findings demonstrated that TTF-1 expression is associated with a longer TTF and OS with erlotinib therapy in patients with NS-NSCLC expressing wild-type EGFR. Thus, TTF-1 expression may serve as a predictive biomarker of the effectiveness of erlotinib monotherapy in such patients.

Mutations in EGFR are powerful predictive biomarkers of the effectiveness of the EGFR-TKIs gefitinib, erlotinib and afatinib. However, only a limited number of studies have evaluated the effectiveness of erlotinib in NSCLC patients with wild-type EGFR.

Shepherd et al reported that erlotinib improved the OS of patients with previously treated unselected advanced NSCLC. That study associated never having smoked with longer

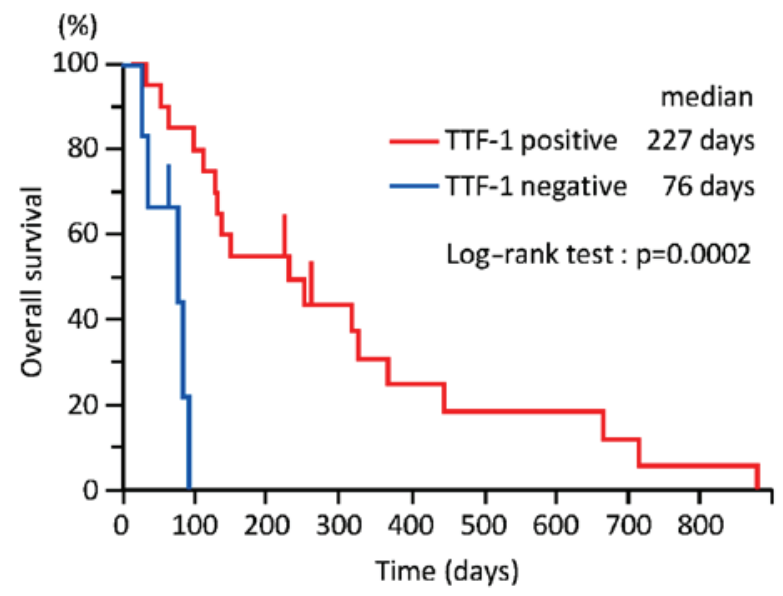

Figure 2. The overall survival was significantly longer in thyroid transcription factor-1 (TTF-1)-positive, compared with that in TTF-1-negative patients (227 vs. 76 days; $95 \%$ confidence interval: $110-366$ vs. $26-90$ days, respectively; $\mathrm{P}=0.0002)$.

progression-free survival (5). Furthermore, the multivariate logistic regression analysis significantly associated smoking status with tumor response in a Japanese phase II study of the effects of erlotinib on previously treated patients with unselected advanced NSCLC (8). However, these studies did not analyze TTF-1. We herein demonstrated that TTF and 
Table III. Overall survival according to the patient characteristics.

\begin{tabular}{|c|c|c|c|c|}
\hline \multirow[b]{2}{*}{ Characteristics } & \multirow[b]{2}{*}{ No. of patients (\%) } & \multicolumn{3}{|c|}{ Univariate analysis } \\
\hline & & HR & $95 \% \mathrm{CI}$ & P-value \\
\hline Gender & & & & 0.73 \\
\hline Male & $12(46)$ & 0.86 & $0.35-2.01$ & \\
\hline Female & $14(54)$ & & & \\
\hline Age, years & & & & 0.09 \\
\hline$\geq 75$ & $1(4)$ & 12.16 & $0.57-126.96$ & \\
\hline$<75$ & $25(96)$ & & & \\
\hline Smoking staus & & & & 0.62 \\
\hline Never & $8(31)$ & 0.80 & $0.31-1.93$ & \\
\hline Ever & $18(69)$ & & & \\
\hline Prior chemotherapy & & & & $0.09^{\mathrm{a}} / 0.84^{\mathrm{b}}$ \\
\hline 1 & $4(15)$ & $0.38^{\mathrm{a}} / 0.86^{\mathrm{b}}$ & $0.10-1.15^{\mathrm{a}}$ & \\
\hline 2 & $17(65)$ & & $0.19-4.40^{\mathrm{b}}$ & \\
\hline$\geq 3$ & $5(19)$ & & & \\
\hline Performance status & & & & $0.93^{\mathrm{a}} / 0.88^{\mathrm{b}}$ \\
\hline 0 & $5(19)$ & $1.05^{\mathrm{c}} / 0.90^{\mathrm{d}}$ & $0.33-2.80^{c}$ & \\
\hline 1 & $15(58)$ & & $0.23-3.85^{\mathrm{d}}$ & \\
\hline 2 & $6(23)$ & & & \\
\hline TTF-1 & & & & 0.002 \\
\hline Positive & $20(77)$ & 0.10 & $0.02-0.43$ & \\
\hline Negative & $6(23)$ & & & \\
\hline
\end{tabular}

Table IV. Post-erlotinib chemotherapy.

\begin{tabular}{|c|c|c|}
\hline \multirow{2}{*}{$\begin{array}{l}\text { Number of } \\
\text { patients receiving } \\
\text { post-erlotinib } \\
\text { chemotherapy }\end{array}$} & \multicolumn{2}{|c|}{ TTF-1 expression } \\
\hline & $\begin{array}{c}\text { Positive } \\
(\mathrm{n}=20)\end{array}$ & $\begin{array}{c}\text { Negative } \\
\quad(n=6)\end{array}$ \\
\hline 0 & 9 & 6 \\
\hline 1 & 6 & 0 \\
\hline 2 & 4 & 0 \\
\hline 3 & 1 & 0 \\
\hline
\end{tabular}

TTF-1, thyroid transcription factor-1.

OS tended to be longer in patients who had never smoked compared with those who previously or currently smoked, but the trend was not statistically significant.

Several investigators have reported an association between TTF-1 expression and the prognosis of NSCLC. A meta-analysis identified TTF-1 as a good prognostic factor for patients with NSCLC, with hazard ratios of 0.64 (95\% CI: 0.41-1.00) and 0.53 (95\% CI: 0.29-0.95) for NSCLC and for a subgroup with adenocarcinoma, respectively (9).

By contrast, others have recently reported an association between TTF-1 expression and chemotherapeutic outcomes.
Grønberg et al associated TTF-1 positivity assessed by immunohistochemistry with prolonged survival among patients with NSCLC who participated in a phase III trial comparing pemetrexed plus carboplatin with gemcitabine plus carboplatin as first-line chemotherapy (10). Furthermore, Sun et al analyzed data from patients with NS-NSCLC treated with pemetrexed-based chemotherapy, and reported a significant association of high TTF-1 protein expression with longer progression-free survival and OS; they also reported that TTF-1 positivity is an independent predictive factor of the effectiveness of EGFR-TKI therapy (11). A significantly higher proportion of our TTF-1-positive patients were further treated with chemotherapy after erlotinib, compared with patients who were TTF-1-negative. Different responses to cytotoxic chemotherapy, and not only to erlotinib, according to TTF-1 expression may have prolonged OS.

This retrospective study of a small patient cohort has several limitations. The majority of the specimens were obtained by transbronchial lung biopsy. In addition, we did not compare the prognosis of patients who did not receive erlotinib according to TTF-1 expression.

In conclusion, erlotinib alone is insufficient to treat patients with previously treated NS-NSCLC expressing wild-type EGFR. However, TTF-1 expression may be a useful tool for predicting the effects of erlotinib in such patients. The present results require confirmation in a large-scale prospective study. 


\section{References}

1. Maemondo M, Inoue A, Kobayashi K, Sugawara S, Oizumi S Isobe $\mathrm{H}$, Gemma A, Harada M, Yoshizawa H, Kinoshita I, et al: Gefitinib or chemotherapy for non-small-cell lung cancer with mutated EGFR. N Engl J Med 362: 2380-2388, 2010.

2. Mitsudomi T, Morita S, Yatabe Y, Negoro S, Okamoto I, Tsurutani J, Seto T, Satouchi M, Tada H, Hirashima T, et al: Gefitinib versus cisplatin plus docetaxel in patients with non-small-cell lung cancer harbouring mutations of the epidermal growth factor receptor (WJTOG3405): An open label, randomised phase 3 trial. Lancet Oncol 11: 121-128, 2010.

3. Zhou C, Wu YL, Chen G, Feng J, Liu XQ, Wang C, Zhang S, Wang J, Zhou S, Ren S, et al: Erlotinib versus chemotherapy as first-line treatment for patients with advanced EGFR mutation-positive non-small-cell lung cancer (OPTIMAL, CTONG-0802): A multicentre, open-label, randomised, phase 3 study. Lancet Oncol 12: 735-742, 2011.

4. Rosell R, Carcereny E, Gervais R, Vergnenegre A, Massuti B, Felip E, Palmero R, Garcia-Gomez R, Pallares C, Sanchez JM, et al: Erlotinib versus standard chemotherapy as first-line treatment for European patients with advanced EGFR mutation-positive non-small-cell lung cancer (EURTAC): A multicentre, open-label, randomised phase 3 trial. Lancet Oncol 13: 239-246, 2012.

5. Shepherd FA, Rodrigues Pereira J, Ciuleanu T, Tan EH, Hirsh V, Thongprasert S, Campos D, Maoleekoonpiroj S, Smylie M, Martins R, et al: Erlotinib in previously treated non-small-cell lung cancer. N Engl J Med 353: 123-132, 2005.
6. Myong NH: Thyroid transcription factor-1 (TTF-1) expression in human lung carcinomas: Its prognostic implication and relationship with expressions of p53 and Ki-67 proteins. J Korean Med Sci 18: 494-500, 2003.

7. Tan D, Li Q, Deeb G, Ramnath N, Slocum HK, Brooks J, Cheney R, Wiseman S, Anderson T and Loewen G: Thyroid transcription factor- 1 expression prevalence and its clinical implications in non-small cell lung cancer: A high-throughput tissue microarray and immunohistochemistry study. Hum Pathol 34: 597-604, 2003.

8. Kubota K, Nishiwaki Y, Tamura T, Nakagawa K, Matsui K. Watanabe K, Hida T, Kawahara M, Katakami N, Takeda K, et al: Efficacy and safety of erlotinib monotherapy for Japanese patients with advanced non-small cell lung cancer: A phase II study. J Thorac Oncol 3: 1439-1445, 2008.

9. Berghmans T, Paesmans M, Mascaux C, Martin B, Meert AP, Haller A, Lafitte JJ and Sculier JP: Thyroid transcription factor 1 - a new prognostic factor in lung cancer: A meta-analysis. Ann Oncol 17: 1673-1676, 2006.

10. Grønberg BH, Lund-Iversen M, Strøm EH, Brustugun OT and Scott H: Associations between, TS and TTF-1, FR- $\alpha$, FPGS, and overall survival in patients with advanced non-small-cell lung cancer receiving pemetrexed plus carboplatin or gemcitabine plus carboplatin as first-line chemotherapy. J Thorac Oncol 8: 1255-1264, 2013

11. Sun JM, Han J, Ahn JS, Park K and Ahn MJ: Significance of thymidylate synthase and thyroid transcription factor 1 expression in patients with nonsquamous non-small cell lung cancer treated with pemetrexed-based chemotherapy. J Thorac Oncol 6: 1392-1399, 2011 